\title{
Zinc-Thiolate Complexes of the Bis(pyrazolyl)(thioimidazolyl)borate Tripods for the Modeling of Thiolate Alkylating Enzymes
}

\section{Mian Ji, Boumahdi Benkmil, and Heinrich Vahrenkamp*}

Institut für Anorganische und Analytische Chemie der Universität Freiburg, Albertstr. 21,

D-79104 Freiburg, Germany

\section{Supporting Information}

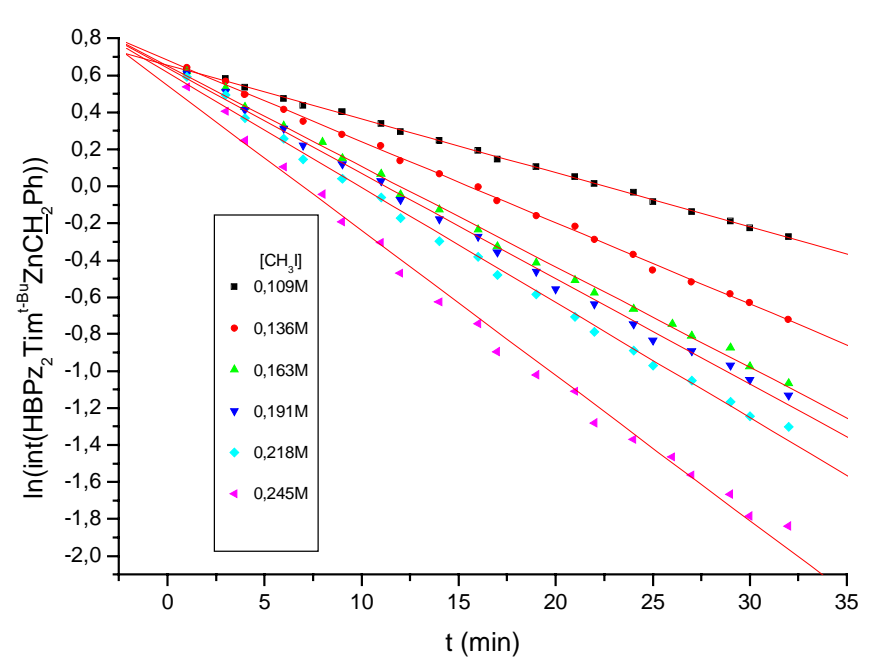

Figure 1. Log plot of the intensities of the ${ }^{1} \mathrm{H}-\mathrm{NMR}$ resonance of the $\mathrm{SCH}_{2}$ group of $\mathbf{L}^{1} \cdot \mathrm{Zn}-\mathrm{SCH}_{2} \mathrm{Ph}$ during the reactions with six different excesses of methyl iodide

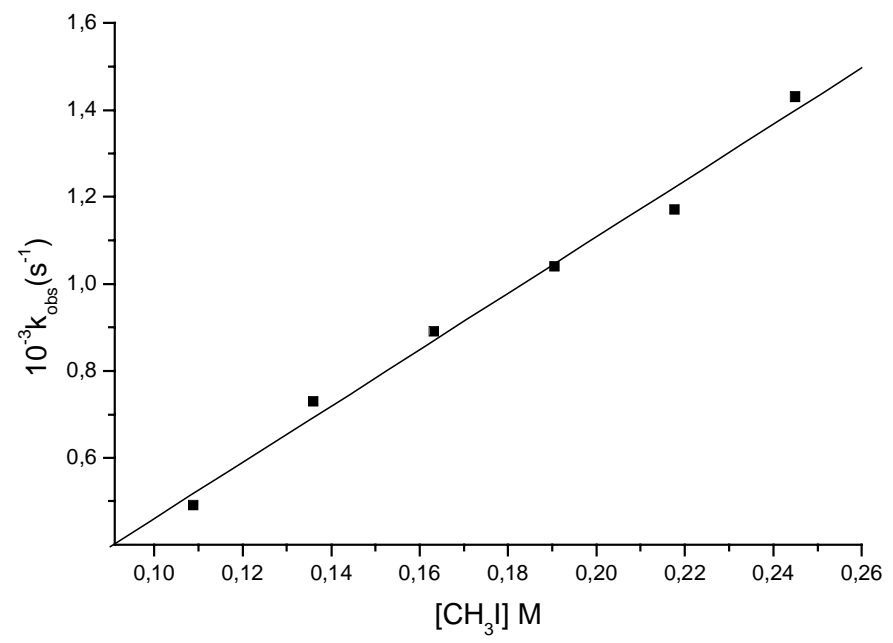

Figure 2. $\mathrm{k}_{\mathrm{obs}}$ as a function of the $\mathrm{CH}_{3} \mathrm{I}$ concentration for the reaction of $\mathbf{L}^{\mathbf{1}} \cdot \mathrm{Zn}-\mathrm{SCH}_{2} \mathrm{Ph}$ with six different excesses of methyl iodide 


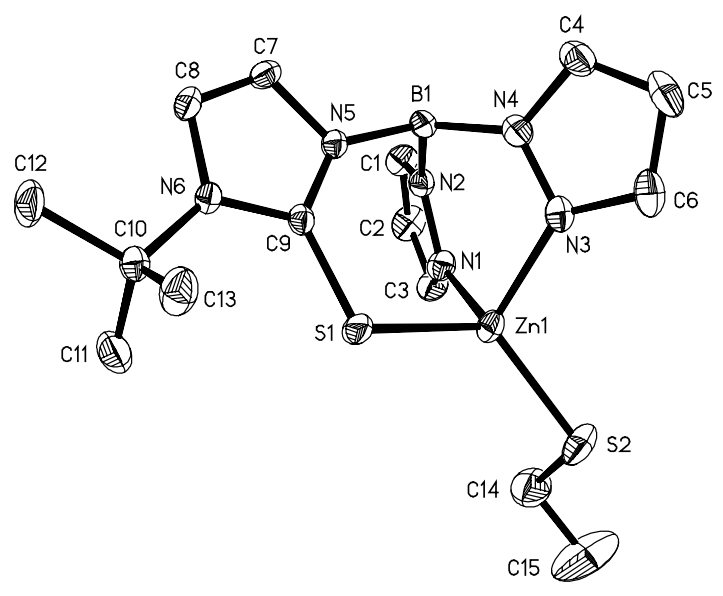

Figure 3. ORTEP plot of $\mathbf{L}^{\mathbf{1}} \cdot \mathrm{Zn}_{-}-\mathrm{SC}_{2} \mathrm{H}_{5}$ (1a)

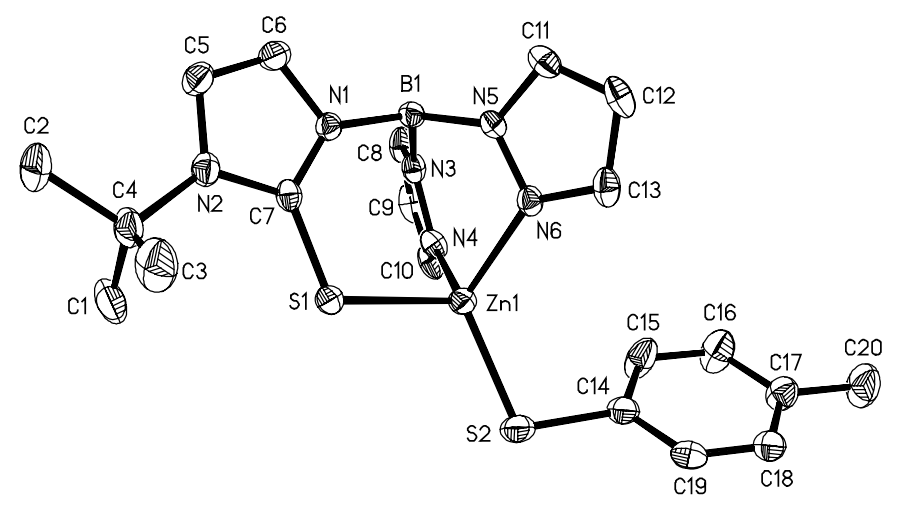

Figure 4. ORTEP plot of $\mathbf{L}^{1} \cdot \mathrm{Zn}_{-} \mathrm{SC}_{6} \mathrm{H}_{4} \mathrm{CH}_{3}$ (1f)

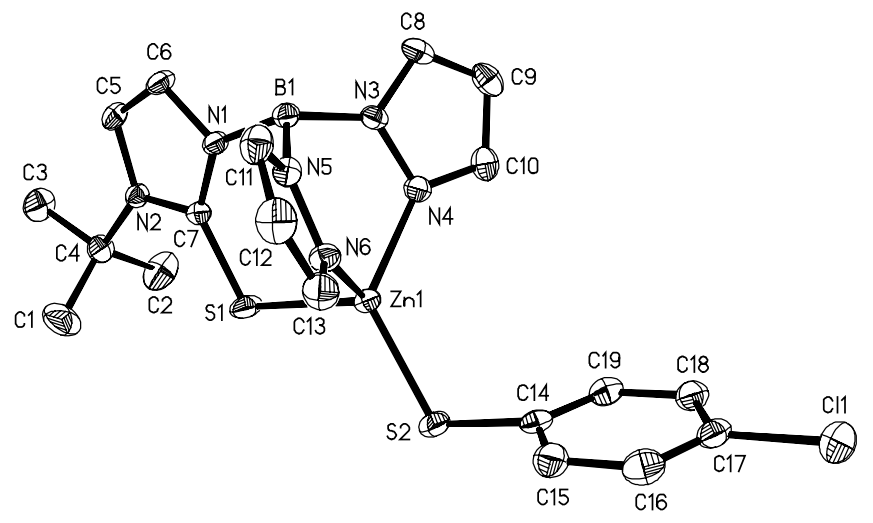

Figure 5. ORTEP plot of $\mathbf{L} \cdot \mathrm{Zn}^{\mathbf{1}}-\mathrm{SC}_{6} \mathrm{H}_{4} \mathrm{Cl}(\mathbf{1 g})$ 


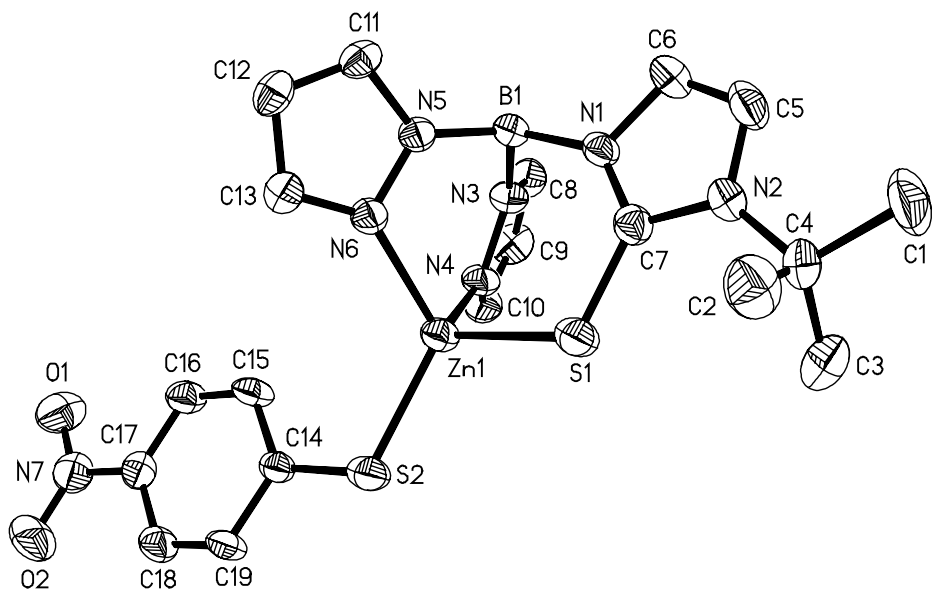

Figure 6. ORTEP plot of $\mathbf{L}^{\mathbf{1}} \cdot \mathrm{Zn}_{-} \mathrm{SC}_{6} \mathrm{H}_{4} \mathrm{NO}_{2}$ (1h), molecule 1

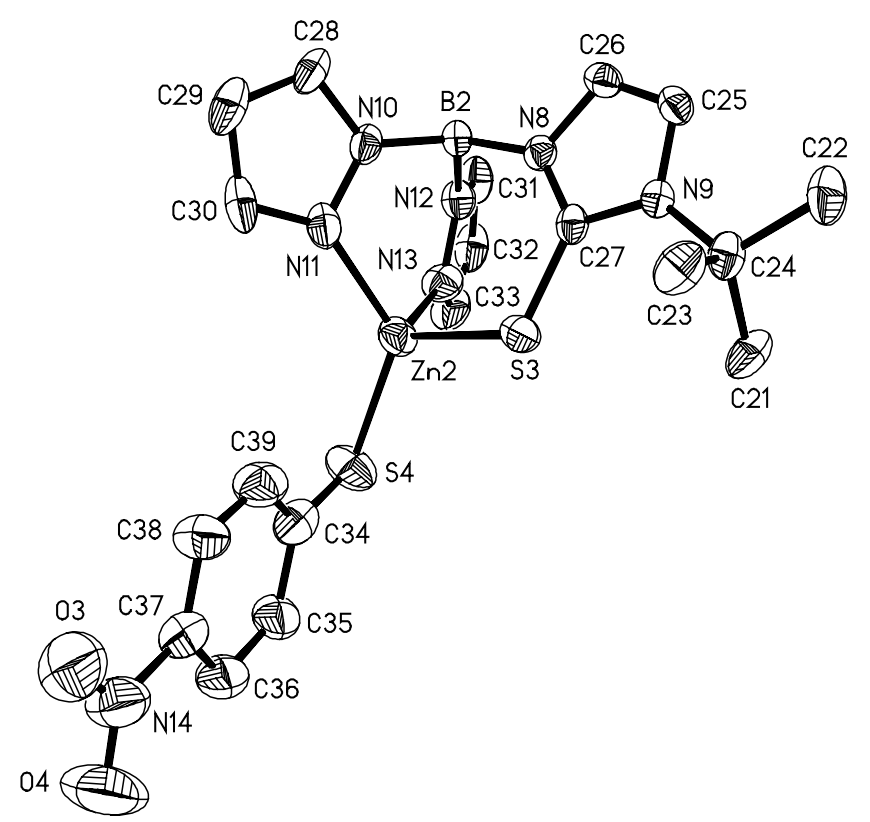

Figure 7. ORTEP plot of $\mathbf{L}^{\mathbf{1}} \cdot \mathrm{Zn}-\mathrm{SC}_{6} \mathrm{H}_{4} \mathrm{NO}_{2}(\mathbf{1 h})$, molecule 2 


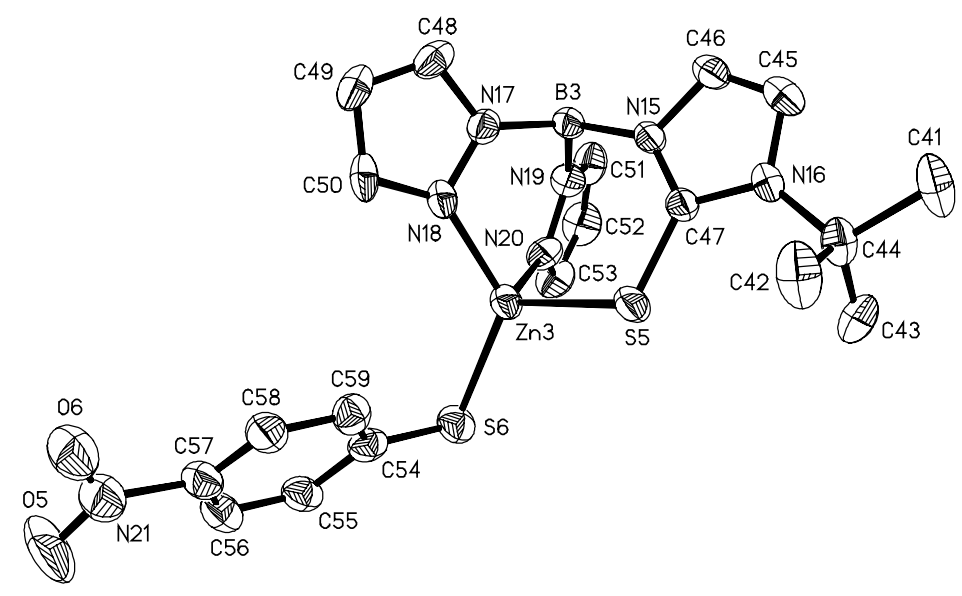

Figure 8. ORTEP plot of $\mathbf{L}^{\mathbf{1}} \cdot \mathrm{Zn}_{-}-\mathrm{SC}_{6} \mathrm{H}_{4} \mathrm{NO}_{2}(\mathbf{1 h})$, molecule 3

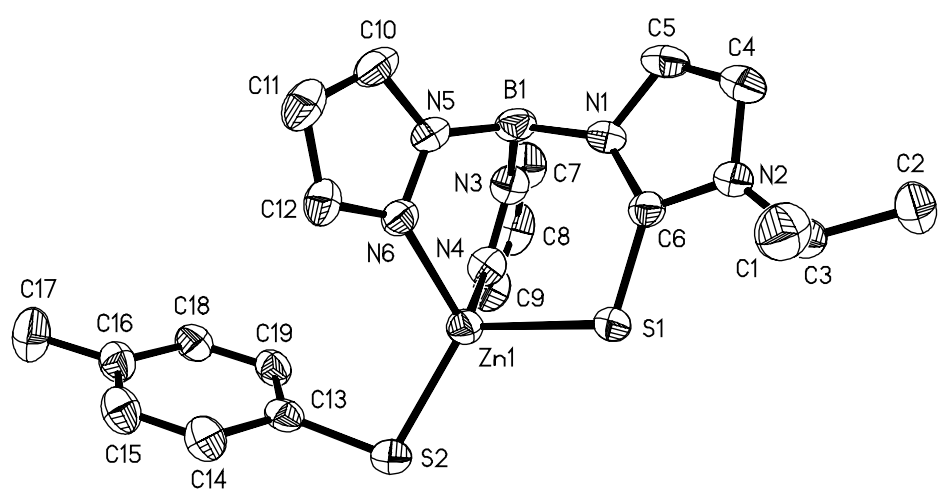

Figure 9. ORTEP plot of $\mathbf{L}^{2} \cdot \mathrm{Zn}_{-} \mathrm{SC}_{6} \mathrm{H}_{4} \mathrm{CH}_{3}$ (2f) 